\title{
Experiencias de lucha y resistencia obrera durante la última dictadura militar: el Gran Rosario 1976-78
}

\author{
Andrés Carminati \\ (UNR/CONICET)
}

\section{Resumen}

En el presente artículo se estudian las diferentes formas que asumió la conflictividad obrera durante la última dictadura militar en la zona de Rosario y el Gran Rosario, en el sub período 1976-1978.

A través de un análisis centrado en lo regional procuramos establecer una periodización y caracterización de acuerdo a las modalidades que fue asumiendo la conflictividad año a año.

Palabras clave: Trabajadores - Conflictividad - Gran Rosario

\begin{abstract}
In this article we study the different forms that have taken the labor conflicts while the last military dictatorship in Rosario and the "Gran Rosario", during the sub period 1976-1978.

Through a regional focused analysis, we seek to establish a chronology and characterization according to the procedure that was assuming the conflict every year.
\end{abstract}

Key words: Workers - Labor conflicts - Gran Rosario

En la última década, los estudios historiográficos sobre la última dictadura militar han crecido notablemente. Un terreno que estaba prácticamente vedado para los análisis históricos -espacio casi exclusivo de sociólogos, juristas, politólogos y periodistas- se fue nutriendo de múltiples y variados acercamientos, desde distintas ópticas y abordajes historiográficos. ${ }^{1}$ Quizá fueron las llamadas "historia reciente", "historia de la memoria" e "historia oral" las puertas de entrada que permitieron colocar las problemáticas en torno a la última dictadura entre las preocupaciones de los historiadores.

1 Ver: AGUILA, Gabriela, "La dictadura militar argentina: interpretaciones, problemas, debates" [en línea], Páginas, revista digital de la escuela de historia, UNR, año1-Nº 1/ Rosario, 2008. <http:// web.rosario-conicet.gov.ar/ojs/index.php/RevPaginas/article/viewFile/9/6>[consulta: 29 marzo 2012].

CARMINATI, Andrés, "Experiencias de lucha y resistencia obrera durante la última dictadura militar: el gran rosario 1976-78”, en Avances del Cesor, Año IX, № 9, 2012, pp. 33-53. 
No obstante, los estudios sobre trabajadores durante el período ocupan un lugar más bien marginal dentro del conjunto de trabajos que han abordado la temática. A las impugnaciones generales que algunos sectores de la academia realizaron sobre la posibilidad de producir estudios sobre "historia reciente", 2 se le suma la vigencia de las diversas tesis sobre la "pérdida de la centralidad del trabajo", ${ }^{3}$ que en última instancia invalidaban o marginaban los estudios sobre trabajadores, procesos de trabajo, clases sociales, etc.

El artículo que presentamos, es parte de un estudio en curso sobre los trabajadores de Rosario y la Zona Norte del Gran Rosario durante la última dictadura militar. En particular abordaremos las diferentes formas de conflictividad durante el sub período 1976-78. ${ }^{4}$ Procura aportar una mirada panorámica sobre los conflictos de la región durante estos tres años, ensayar una periodización y establecer las diferencias y continuidades en las modalidades de la confrontación. ${ }^{5}$

\section{Un repaso historiográfico}

Si bien, como afirmamos, la problemática de los "trabajadores durante la última dictadura" no ha ocupado el centro de las discusiones historiográficas en los estudios del período, contamos con una serie de trabajos que, en diferentes tiempos y con diversas ópticas, han abordado la temática. Podríamos demarcar tres "momentos" en lo que hace a la producción académica sobre el tema.

Un primer momento, desde el ocaso de la dictadura hasta finales de los años ' 80 , donde se escriben los primeros trabajos, y que al igual que los estudios más generales sobre el período, cuenta con aportes de politólogos, abogados, sociólogos y algunos historiadores. ${ }^{6}$

2 Ver: FRANCO, Marina y LEVÍN, Florencia, "El pasado cercano en clave historiográfica", en FRANCO, Marina y LEVÍN, Florencia (compiladores) Historia Reciente. Perspectivas y desafíos para un campo en construcción, Paidós, Buenos Aires, 2007. pp.31-65.

3 Ver: ANTUNES, Ricardo, ¿Adiós Al Trabajo? Ensayo sobre las metamorfosis y el rol central del mundo del trabajo, Herramienta, Buenos Aires, 2003; DE LA GARZA, Enrique, “¿Fin del Trabajo o Trabajo sin Fin?" en CASTILLO, Juan José (editor) El Trabajo del Futuro, Editorial Complutense, Madrid, 1999.

4 La mayor parte de los autores sostienen que a partir del primer llamado a huelga general durante abril de 1979 se produce un cambio de etapa. En función de ello y de la necesidad de analizar en profundidad estos primeros años es que nos abocamos al estudio del sub período 1976-78.

5 En trabajos previos nos hemos detenido en conflictos puntuales ocurridos durante el período en la región. En este artículo trabajaremos los diferendos con menor detenimiento, insertándolos en una periodización más amplia que nos permite ver el movimiento de conjunto.

6 DELICH, Francisco, "Después del diluvio, la clase obrera", en ROUQUIÉ, Alain (compilador) Argentina, hoy, Siglo XXI, México, 1982, pp. 129-151; DELICH, Francisco, "Desmovilización social, reestructuración obrera y cambio sindical", en WALDMAN, Peter y GARZÓN VALDÉS, Ernesto, 
Un segundo momento, que abarca la década de los ' 90 completa, caracterizado por una muy escasa producción historiográfica sobre la problemática específica; ${ }^{7}$ y un tercer momento que se inaugura a comienzos del siglo XXI, donde emergen un número considerable de nuevas investigaciones, que retoman algunos de los interrogantes de los primeros estudios, a la par que inauguran nuevas miradas, preguntas y modos de abordaje. ${ }^{8}$

Un punto en el que se destacan los cambios producidos en la historiografía entre el primero y el tercer momento es, sin lugar a dudas, el de la escala de análisis. Mientras que los estudios de la década de los ' 80 se planteaban como objeto de estudio el movimiento obrero y/o la clase obrera de Argentina -aún cuando muchas veces se trataba de análisis que se circunscribían a Capital Federal o el Gran Buenos Aires- los estudios más recientes,

El Poder militar en la Argentina, 1976-1981, Galerna, Buenos Aires, 1983, pp. 101-115; FALCÓN, Ricardo, "Conflicto Social y régimen militar. La resistencia obrera en Argentina", en GALITELLI, Bernardo y THOMPSON, Andrés, Sindicalismo y regímenes militares en Argentina y Chile, CEDLA, Amsterdam, 1982; GALITELLI, Bernardo y THOMPSON, Andrés, "La situación laboral en la Argentina del 'Proceso', 1976-1981", en GALITELLI, Bernardo y THOMPSON, Andrés (compiladores) Sindicalismo y..., Op. Cit.; CHÁVES, Gonzalo, Las luchas sindicales contra el Proceso. 1976-1980: Cinco Años de Resistencia, La Causa, Buenos Aires, 1983; BIEBER, León, "El movimiento obrero argentino a partir de 1976. Observaciones al trabajo de Francisco Delich", en WALDMAN, Peter y GARZÓN VALDÉS, Ernesto, El Poder militar..., Op. Cit., pp. 116-122; ABÓS, Álvaro, Las organizaciones sindicales y el poder militar (1976-1983), CEAL, Buenos Aires, 1984; FERNANDEZ, Arturo, Las prácticas sociales del sindicalismo (1976-82), CEAL, Buenos Aires, 1984; ALMEYRA, Guillermo, "La clase obrera en la Argentina actual", en PLA, Alberto, ALMEYRA, Guillermo y otros, La Década Trágica. Ocho ensayos sobre la crisis argentina 1973-1983, Tierra del Fuego, México, 1984; CALELLO, Osvaldo y PARCERO, Daniel, De Vandor a Ubaldini, CEAL, Buenos Aires, 1984, V. I y II; POZZI, Pablo, Oposición Obrera a la Dictadura (1976-1982), Buenos Aires, Contrapunto, 1987.

7 BITRÁN, Rafael y SCHNEIDER, Alejandro, "Dinámica social y clase trabajadora durante la dictadura militar de 1976-1983. Estudio de la zona norte del Gran Buenos Aires, en particular de las fábricas Del Carlo y Ford Motors", en Nuevas tendencias en el sindicalismo: Argentina-Brasil, BiblósFundación Simón Rodríguez, Buenos Aires, 1992; SIMONASSI, Silvia, "De obreros e historiadores. Notas acerca de la historiografía sobre la clase obrera argentina de las décadas de 1960 y 1970 " en Cuadernos del CIESAL, 2da.época, Año 4, №5, Rosario, 1998. Junto a la reedición del artículo de Falcón: FALCÓN, Ricardo, "La resistencia obrera a la dictadura militar (una reescritura de un texto contemporáneo a los acontecimientos)" en Quiroga, Hugo y Tcach, César (compiladores) A veinte años del golpe. Con memoria democrática, Homo Sapiens, Buenos Aires, 1996; y un artículo de Pablo Pozzi, que es prácticamente una reedición de un capítulo de su libro: POZZI, Pablo, "Argentina 1976-1982: resistencia obrera y apertura democrática”, en Estudios Latinoamericanos, № 15, 1992.

8 Citaremos algunos de ellos en los siguientes puntos. 
casi sin excepción, se focalizan en una región determinada, ${ }^{9}$ una fábrica, ${ }^{10}$ sector de trabajo o algún conflicto particular durante el período. ${ }^{11}$

Otra modificación notable ha sido el cambio respecto al énfasis en las dirigencias sindicales, propias de la historia tradicional del movimiento obrero, frente a nuevos estudios que han procurado recuperar las historias y/o experiencias de un determinado colectivo de trabajadores. Si bien la mayor parte de los trabajos del primer período se distinguen por hacer mayor énfasis en las dirigencias, en tanto los últimos corresponden con la segunda descripción, no es una distinción tajante. Tanto el trabajo de Ricardo Falcón, ${ }^{12}$ del año 1982, como el de Pablo Pozzi, ${ }^{13}$ de 1987, procuraron estudiar la conflictividad obrera desde una perspectiva centrada en las fábricas o lugares de trabajo; mientras que el trabajo de Daniel Dicósimo ${ }^{14}$ del año 2006, estudia el "comportamiento sindical" en dos gremios de la zona del Sur de la provincia de Buenos Aires (si bien lo hace desde una perspectiva regional y desde ópticas renovadoras).

Un hilo de continuidad se puede hallar en el reiterado debate acerca de dos temáticas que, simplificando matices, se resumen en la discusión sobre "la inmovilidad o resistencia"

9 BITRÁN, Rafael y SCHNEIDER, Alejandro, "Dinámica social...", Op. Cit.; SCHNEIDER, Alejandro. "'Ladran Sancho...' Dictadura y clase obrera en la zona norte del Gran Buenos Aires" en POZZI, Pablo, CAMARERO, Hernán y SCHNEIDER, Alejandro (Compiladores) De la Revolución Libertadora al Menemismo. Historia social y política argentina, Imago Mundi, Buenos Aires, 2003; DICÓSIMO, Daniel, "Dirigentes sindicales, racionalización y conflictos durante la última dictadura militar" en Entrepasados, Nro. 29, principios de 2006; CARMINATI, Andrés, "Conflictividad obrera durante la última dictadura militar en Rosario y el 'Cordón Norte del Gran Rosario'. El otoño caliente de junio de 1977" en DICÓSIMO, Daniel y SIMONASSI, Silvia (compiladores) Trabajadores y empresarios en la Argentina del siglo XX: indagaciones desde la historia social, Prohistoria, Rosario, 2011.

10 GRESORES, Gabriela "Conflictos obreros en la industria frigorífica bajo la dictadura militar: La huelga larga de Swift de Berisso", en Ciclos, Año XI, V. IX, No 22, $2^{\circ}$ semestre de 2001; BARRAGÁN, Ivonne, "Acción obrera durante la última dictadura militar, la represión en una empresa estatal. Astillero Río Santiago (1974-1984)", en BASUALDO, Victoria (coordinadora) La clase trabajadora argentina en el Siglo XX: Experiencia de lucha y organización, Cara o Ceca, Buenos Aires, 2011.

11 RÍOS, Sabrina, "Trabajadores durante la dictadura militar (1976-1983). Prácticas y memorias desde un estudio de caso", ponencia en $X I^{\circ} J I / D H$, UNT, Tucumán, septiembre de 2007 (sobre la fábrica Alpargatas); GHIGLIANI, Pablo, "El conflicto de Luz y Fuerza de 1976-1977: ensayo de interpretación", Ponencia en IV Seminario Internacional Políticas De La Memoria, Buenos Aires, 29 y 30 de septiembre, $1^{\circ}$ de octubre de 2011.

12 FALCÓN, Ricardo, "Conflicto Social...", Op. Cit.

13 POZZI, Pablo, Oposición Obrera..., Op. Cit.

14 DICÓSIMO, Daniel, "Dirigentes sindicales...", Op. Cit. 
de los trabajadores durante la dictadura, y la cuestión de la relación entre las dirigencias y las bases sindicales.

Respecto al primer ítem, se pueden hallar dos hipótesis distintas, con sus respectivos matices y tonos. Por un lado existe una tesis que plantea un escenario de inmovilidad de los trabajadores durante la dictadura, a la par que se vislumbran transformaciones profundas en la composición de la clase obrera como consecuencias ex post facto. Su visión más difundida se encuentra en los dos artículos de Francisco Delich ${ }^{15}$, y puede sintetizarse en el siguiente párrafo:

... durante cinco años [1976-81], la clase obrera argentina y sus sindicatos permanecieron, en conjunto, inmóviles desde el punto de vista social y de la actividad sindical. ${ }^{16}$

En sentido contrario otros autores plantean un fuerte protagonismo de los trabajadores en la resistencia y oposición a la dictadura. Ejemplificaremos con citas de dos autores que expresan algunos matices. Ricardo Falcón planteaba entre las conclusiones de su estudio, que analiza cerca de 300 conflictos, que se evidenciaba un:

...sorprendente vigor de los trabajadores argentinos en la resistencia a la ofensiva combinada del Estado y de los capitalistas. Sin duda que las varias centenas de luchas que se registraran durante esos cinco años pusieron algunos límites de importancia a este ataque, aunque no pudieron impedir en su conjunto una grave deterioración de sus condiciones de vida y de trabajo. ${ }^{17}$

Por su parte Pablo Pozzi destacaba que:

El movimiento obrero organizado fue la principal fuerza social que se opuso al Proceso, así como los familiares fueron la principal fuerza moral. Sin embargo, el sindicalismo a nivel dirigente no fue decidido adversario del régimen. ${ }^{18}$

De la última cita se desprende el segundo eje en debate: el accionar diferenciado entre las bases sindicales y las cúpulas dirigentes. Mientras algunos autores han hecho especial énfasis en la lucha "solitaria" de las bases frente a una dirigencia "claudicante", otros estudios tienden a rescatar los comportamientos de una de las fracciones en que se dividió el movimiento organizado: "los 25"/CGT Brasil. ${ }^{19}$ En tanto que Álvaro Abós plantea una

15 DELICH, Francisco, "Después del diluvio...", Op. Cit. y DELICH, Francisco, "Desmovilización social...", Op. Cit.

16 DELICH, Francisco, "Desmovilización social...", Op. Cit., p. 101.

17 FALCÓN, Ricardo, "Conflicto social...", Op. Cit.p.130.

18 POZZI, Pablo, Oposición Obrera..., Op. Cit., p.179.

19 CALELlO, O. y D. PARCERO, De Vandor..., Op. Cit., y FERNANDEZ, A., Las prácticas..., Op. Cit. 
suerte de complementariedad entre la corriente "contestataria" y la "dialoguista", que según el autor actuaban como "dos ramas del mismo tronco": "Una golpeaba y la otra ganaba los espacios que la confrontación dejaba vacíos". ${ }^{20}$

En la mayor parte de los estudios que componen lo que hemos denominado segundo y tercer momento se ha pasado revista de estos debates y se han asumido posturas de manera explícita o implícita. A la par, los estudios más recientes han planteado nuevas cuestiones como son: las militancias partidarias en las fábricas, sus roles y actitudes; la "cuestión regional" que aludimos antes; los comportamientos de las patronales durante el período y distinto tipo de responsabilidades en la represión; ${ }^{21}$ las problemáticas de la "memoria" y el uso de fuentes orales, etc.. Relacionado con este último punto, se evidencia en los aportes más recientes la preocupación por el acceso a nuevas fuentes, como han sido los denominados "archivos de la represión" (por ejemplo, el archivo de la ex DIPBA), y la problematización sobre sus usos.

\section{La dictadura frente a los trabajadores}

Las severas condiciones que el régimen iniciado el 24 de marzo impuso al conjunto de la clase trabajadora y sus organizaciones, alteraron parcialmente las formas en las cuales se había manifestado la conflictividad obrera en la Argentina hasta ese momento. La suerte de cruzada restauradora que la dictadura emprendía sobre el conjunto de la sociedad tuvo, respecto de los trabajadores, formas específicas. El régimen llevó a cabo dos estrategias fundamentales: una dentro del marco de la "legalidad" autoritaria, caracterizada por una batería de regulaciones que sancionaba penalmente toda forma de conflicto obrero (abriendo de ese modo las puertas a la represión directa de los mismos); a la par que disponía la intervención de la CGT y los sindicatos más importantes. Se modificó la Ley de Contrato de Trabajo y se implementaron una serie de medidas de carácter regresivo que afectaban la estabilidad en el empleo, el derecho a las peticiones colectivas y se suspendían las paritarias salariales. La otra modalidad estuvo signada por la aplicación sistemática del Terrorismo de Estado, que alcanzó a aquellos trabajadores catalogados como delincuentes subversivos. Diferentes estudios indican que alrededor del $50 \%$ de las personas que figuran como detenidos desaparecidos eran trabajadores: obreros y empleados. ${ }^{22}$

20 ABÓS, A, Las organizaciones..., Op. Cit., p.100.

21 BASUALDO, Victoria, "Complicidad patronal militar en la última dictadura argentina. Los casos de Acindar, Astarsa, Dálmine-Siderca, Ford, Ledesma y Mercedes-Benz", en Suplemento especial de Engranajes, a 30 años del golpe militar, FETIA-CTA, marzo de 2006; SIMONASSI, Silvia, " "A trabajar y muzzarella'. Prácticas y políticas de disciplinamiento laboral en la industria metalúrgica de Rosario, 1974-1983”, Historia Regional, № 25, Villa Constitución, 2007.

22 FERNÁNDEZ, Arturo, Las prácticas..., Op. Cit., p. 57; COMISIÓN NACIONAL SOBRE LA DESAPARICIÓN DE PERSONAS (CONADEP), Nunca Más. Informe de la Comisión Nacional 
Si bien la represión hacia el movimiento obrero había comenzado hacia mediados de 1974, particularmente sobre aquellos sectores de lo que se denominó el sindicalismo clasista o combativo, la instauración de la dictadura constituye indudablemente un salto cuantitativo y cualitativo en este sentido.

Las políticas dictatoriales sobre el movimiento obrero tenían como objetivos frenar la movilización social abierta en 1969 y minar las estructuras de organización obrera en sus distintos niveles: reducir a su mínima expresión el "poder obrero" a nivel de fábrica -comisiones internas, delegados-y reestructurar y reducir las organizaciones sindicales de segundo y tercer nivel.

El discurso procesista aludía a estos objetivos haciendo referencia al "combate" contra la "subversión en el ámbito fabril", ${ }^{23}$ una de las "manifestaciones" que según los militares y sus voceros asumía la "multiforme delincuencia subversiva". Mientras que al sindicalismo en general se lo caracterizaba como "corrupto", "politizado" y "desnaturalizado de sus fines específicos". La CGT y las estructuras sindicales más importantes fueron intervenidas desde el mismo 24 de marzo en procura de impedir cualquier acción coordinada de las direcciones gremiales tradicionales, a la par que se concebían planes para una nueva ley de Asociaciones Profesionales. En tanto que a la subversión del ámbito fabril se destinaron las metodologías de "contrainsurgencia" en vigencia durante el período. El mismo día del golpe fueron rodeados los ingresos de numerosos establecimientos fabriles con el objeto de detener a delegados, comisiones internas y activistas previamente "marcados" por los distintos aparatos de inteligencia y/o las direcciones empresarias. ${ }^{24}$ Paralelamente las "patotas" allanaban domicilios de activistas, militantes sindicales y/o "sospechosos" de serlo, con las modalidades ya descriptas en el informe de la CONADEP ${ }^{25}$ donde primaba la nocturnidad y el anonimato.

Asimismo, el control fue intensificado en las plantas industriales y sus alrededores: en algunas fábricas, en conjunto con las fuerzas de seguridad, se procedió a la identificación masiva de los trabajadores a través de la cédula federal u otros medios de individualización y control, que posteriormente servían tanto para controlar el ingreso en las plantas como para atravesar los retenes militares o policiales que existían en los principales accesos fabriles. ${ }^{26}$

sobre la Desaparición de Personas, Buenos Aires, EUDEBA, 1985, p. 375; IZAGUIRRE, Inés, "Los desaparecidos, recuperación de una identidad expropiada", Cuaderno 9, Fac. de Ciencias Sociales, UBA, Buenos Aires, 1992.

23 Declaraciones del Ministro de Trabajo, Tomás Liendo, La Capital, Rosario, 2/05/1976.

24 BASUALDO, Victoria "Complicidad patronal...", Op. Cit.

25 CONADEP, Nunca Más..., Op. Cit.

26 CARMINATI, Andrés “ “ ‘...Con los pies de plomo, y calladito la boca...'. Actitudes y experiencias de los trabajadores industriales del Cordón del Paraná en el contexto dictatorial (1976-1979)”, ponencia XII JI/DH, Bariloche, octubre de 2009. 
La estabilidad en el empleo se vio seriamente afectada debido a la discrecionalidad con que pudieron manejarse las direcciones empresarias, que hicieron amplio uso del despido por razones disciplinarias y/o productivas. ${ }^{27}$ Hasta 1979 los reclutamientos de personal se realizaban de manera provisional, sujetos a los informes de los servicios de inteligencia. ${ }^{28}$

Asimismo, las consecuencias del plan económico de la dictadura, fueron catastróficas para los trabajadores. Al finalizar la dictadura se había producido una profunda redistribución del ingreso en perjuicio de los trabajadores, y una radical reformulación del aparato productivo, que afectó algunos sectores y ramas de la producción, produjo el cierre de múltiples plantas pequeñas y medianas, y algunas grandes, con sus efectos sobre el empleo y las condiciones de trabajo. El Producto Bruto Industrial tuvo una caída de un $20 \%,{ }^{29}$ en tanto la fuerza de trabajo empleada en el sector se redujo en un $31 \%$ entre 1975 y $1981 .{ }^{30} \mathrm{El}$ salario real sufrió una caída porcentual de 32 puntos entre el 1974 y el 1982, y la participación en el PBI se redujo del $49,3 \%$ en 1975 al $33 \%$ en $1981 .{ }^{31}$

Esta somera descripción de la magnitud de la represión y de los diversos aspectos que tuvo la ofensiva contra los trabajadores y sus organizaciones es imprescindible para comprender las condiciones de posibilidad y desarrollo de la protesta obrera en el período.

\section{La conflictividad durante la dictadura}

A raíz de la magnitud y alcance de las medidas represivas, económicas y normativas que el régimen impuso al conjunto de la clase trabajadora, la modalidad de los conflictos durante el período sufrió ciertas transformaciones y adaptaciones coyunturales.

Durante los primeros años de la dictadura (hasta 1979 o 1981 según los distintos autores) predominaron formas de la conflictividad que en su conjunto han sido denominadas como resistencia molecular. Siguiendo los trabajos Falcón, Almeyra y Pozzi, ${ }^{32}$ haremos uso de la caracterización de resistencia molecular para denominar aquellas modalidades de enfrentamiento centradas fundamentalmente en los lugares de trabajo, caracterizadas por su dispersión y falta de coordinación con otros centros laborales; en general definida por medidas menos abiertas en la confrontación. Esto incluiría acciones de diverso tenor, algunas de las cuales sólo pueden ser vistas como contenciosas a la luz del contexto ultra

27 SIMONASSI, Silvia, ““A trabajar y muzzarella'...”, Op. Cit.

28 DELICH, Francisco, "Desmovilización social...”, Op. Cit., p.107.

29 KATZ, Jorge y KOSACOFF, Bernardo, El proceso de industrialización en la Argentina: evolución, retroceso y prospectiva. CEPAL/CEAL, Buenos Aires, 1989. p. 61.

30 FERNANDEZ, Arturo, Las prácticas..., Op. Cit., p. 54.

31 FERNÁNDEZ, Arturo, Las prácticas..., Op. Cit., p. 109.

32 FALCÓN, Ricardo, "La resistencia...", Op. Cit.; ALMEYRA, Guillermo, "La clase obrera....", Op. Cit.; POZZI, Pablo, Oposición..., Op. Cit. 
represivo y de una correlación de fuerzas desfavorable para los trabajadores. Las huelgas se caracterizaron por su corta duración, en general aisladas, y en muchos casos tomando sólo algunas secciones. Dentro de esta lógica, fueron muy frecuentes las modalidades de "huelga de brazos caídos", "trabajo a tristeza", "trabajo a reglamento" o el "quite de colaboración". Estas últimas son dos modalidades a través de las cuales los trabajadores afectan la producción negándose a realizar horas extras o tareas no incluidas en los convenios colectivos de trabajo. Por lo general todos los planes de producción contemplaban su realización, por lo que la aplicación de estas medidas por parte de los trabajadores alteraba sensiblemente el orden productivo. Mientras que el trabajo a "desgano" o "tristeza" son medios para disminuir o suspender la actividad laboral con permanencia en el lugar de trabajo.

En algunos establecimientos el enfrentamiento tomó la forma de sabotaje a la producción y/o a las instalaciones fabriles. Sobre estos hechos nos parece pertinente señalar dos cosas: por un lado tienen su antecedente histórico-político en la denominada "resistencia peronista", y por tanto forman parte de la experiencia de la clase trabajadora argentina. Por el otro, algunas organizaciones armadas con inserción fabril alentaban a sus militantes, simpatizantes y trabajadores en general a producir hechos de sabotaje, a la vez que se adjudicaron como propios algunos de dichos actos. ${ }^{33}$

Otras formas de protesta, propias de la denominada resistencia molecular, puede observarse en aquellas que buscaban entorpecer el ritmo y la disciplina laboral, como las "campañas de ruidos", "aplaudidas", o en las acciones consistentes en "tirar gamexane", etc. ${ }^{34}$

El común denominador de este conjunto de medidas era la producción de acciones de protesta que pudieran tener cierto efecto sobre la producción o la disciplina fabril manteniendo a resguardo o en el anonimato a los manifestantes; ya fuera a través de acciones unánimes, sin dirigencias aparentes, o de acciones clandestinas, en el caso de los sabotajes.

En síntesis, se trataría de un amplio abanico de medidas que pueden ser concertadas o individuales, limitadas en sus dimensiones temporales y espaciales.

Si bien el escenario dominante durante el primer trienio de la dictadura estuvo signado por esta tonalidad de conflictos de baja intensidad, reducidos a espacios acotados, de carácter breve y en general aislados del conjunto, hubo ciertos momentos en que se produjeron estallidos de conflictividad, donde varios sectores de trabajo se lanzaron de manera más o menos simultánea a la huelga. Así sucedió en agosto/septiembre de 1976 con una serie de conflictos en la industria automotriz, que tuvo amplia repercusión en Córdoba y el Gran

33 Por ejemplo, el editorial “Un arma de combate ¡SABOTAJE A LA PRODUCCIÓN!” de El Combatiente $\mathrm{N}^{\mathrm{o}} 212,14 / 4 / 1976$. Que fue distribuido como panfleto en la puerta de algunas fábricas: DI. No3050 - Caja 50- 21 /5/ 1976, San Lorenzo. Y en Evita Montonera No13, abril-mayo 1976, órgano de Montoneros: "Directivas para las agrupaciones" [...] El sabotaje como forma clandestina de ataque a los monopolios, debe hacerse sobre la producción evitando dañar la fuente de trabajo".

34 DICÓSIMO, Daniel, "Desobediencia laboral en la industria metalúrgica, durante el Proceso de Reorganización Nacional. 1976-1980”, Ponencia XI JI/ H, Tucumán, 19 al 22/09/ 2007. 
Buenos Aires ${ }^{35}$ o durante una "ola" de conflictos en la zona de Rosario y el Gran Rosario en junio de 1977, ${ }^{36}$ que se extendió durante diez días y abarcó diferentes plantas y sectores de trabajo. También en octubre y noviembre de ese año, cuando estallaron una serie de conflictos "que sin tener una conducción única, coincidieron en el tiempo, movilizando cerca de un millón de trabajadores. Hubo huelgas y paros en el transporte de corta, media y larga distancia, en subterráneos, en ferrocarriles, y en los sectores metalúrgico, textil, mecánico, bancario, etc.". ${ }^{37}$

Atento a esta caracterización general procuraremos describir y analizar el desarrollo histórico concreto de la conflictividad en la zona de Rosario y el Cordón Industrial de la Zona Norte del Gran Rosario durante los años 1976, ${ }^{38} 1977$ y 1978.

\section{La conflictividad obrera en La zona de Rosario y el Cordón Industrial de la Zona Norte del Gran Rosario 1976-78}

La zona de estudio está inserta en lo que se denomina "Cordón Industrial del Paraná", que se extiende a la orilla del río del mismo nombre, desde la Zona Norte del Gran Rosario hasta San Nicolás en la provincia de Buenos Aires. En su conjunto es uno de los centros industriales más importantes del país, donde se concentran grandes plantas de industrias básicas como la petroquímica, química, siderúrgica; numerosas plantas metal mecánicas, metalúrgicas, aceiteras, cerámicas, textiles, etc.

La región posee una larga tradición de luchas obreras, que pueden rastrearse hasta fines del siglo XIX. Durante el período previo al golpe de Estado pueden destacarse los Rosariazos de 1969 (en particular, el segundo), los acontecimientos conocidos como el Villazo y la experiencia de la UOM de Villa Constitución; ${ }^{39}$ en tanto que en la Zona Norte sobresalen la conducción "antiburocrática" del SOEPU en la planta PASA y las experiencias de la CGT San Lorenzo y la "Intersindical de Gremios", entre el '71 y el '74, que agrupaba sindicatos y comisiones internas "combativas". ${ }^{40}$

Antes del 24 de marzo, las diversas políticas anti sindicales que Juan Carlos Torre

35 ABÓS, Álvaro, Las organizaciones..., Op. Cit., p. 9; POZZI, Pablo, Oposición..., Op. Cit., p.71.

36 CARMINATI, Andrés, "Conflictividad obrera...", Op. Cit.

37 FERNANDEZ, Arturo, Las prácticas..., Op. Cit., p. 91.

38 El año 1976 lo abordaremos desde el 24 de marzo.

39 RODRÍGUEZ, Ernesto y VIDELA, Oscar (compiladores) El Villazo. La experiencia de una ciudad y su movimiento obrero, Revista Historia Regional Libros, Villa Constitución, 1999.

40 CERUTI, Leónidas y RESELS, Mariano, Democracia Directa y Gestión Obrera. El S.O.E.P.U., La Intersindical de San Lorenzo y la Coordinadora de Gremios. 1962-1976, Del Castillo, Rosario, 2006. 
denominó "supresión de la oposición sindical", ${ }^{41}$ apuntaron preferentemente hacia los referentes y estructuras de estas experiencias mencionadas. La sanción de diversas leyes de carácter represivo (reforma del Código Penal, ley 20642; "Ley de Seguridad Nacional", $20840^{42}$ y decretos $261 / 75,2770,2771$ y $2772^{43}$ ) y la modificación de la Ley de Asociaciones Profesionales (20615), que concedía a las Centrales amplias facultades para intervenir las seccionales, anular decisiones de comités fabriles o expulsar a los miembros díscolos, fueron dos herramientas utilizados por el ministerio de Trabajo y la dirigencia sindical tradicional para empezar a desarticular las diversas experiencias sindicales alternativas, autodenominadas "clasistas", "combativas" o "antiburocráticas".

Uno de los hechos más destacados en nuestra zona de estudio fue el "mega operativo" de fuerzas conjuntas que se realizó en marzo de 1975, denominado "Operativo Serpiente Roja del Paraná". Durante el mismo se realizó una enorme razia desde Zárate Campana hasta Puerto San Martín, con epicentro en la ciudad santafesina de Villa Constitución. Como resultado del suceso se produjeron alrededor de 300 detenciones entre dirigentes gremiales, delegados y militantes a lo largo del "Cordón".

En paralelo con esta política represiva de carácter legal, en las postrimerías del gobierno de Isabel Perón se produjo un incremento del accionar de bandas paramilitares que produjeron numerosos atentados contra delegados, activistas fabriles y militantes.

Con esto queremos indicar que, al comenzar la dictadura, el activismo y las organizaciones de base en las fábricas ya venían sufriendo una cierta dispersión y desintegración. Incluso muchos militantes, delegados y miembros de comisiones internas fueron echados en los días posteriores al golpe, y otros, según testimonios que hemos podido recoger, decidieron, por seguridad, no volver a sus lugares de trabajo.

Atentos a los resultados que arroja el estado actual de nuestra investigación, dividiremos en cuatro etapas el estudio del período 1976-78. Un primer subperíodo, entre marzo del '76 y junio del ' 77 , signado mayormente por acciones inscriptas dentro de lo que hemos denominado como resistencia molecular, con la excepción de dos momentos que señalaremos más adelante. Un segundo subperíodo, que a su vez dividiremos en dos, donde encontramos dos lapsos de estallidos simultáneos de conflictos: Una "ola de huelgas" durante junio de 1977, que se extendió por Rosario y la Zona norte del Cordón Industrial, y una segunda "ola" que afectó varios centros urbanos del país entre los meses de octubre y diciembre del

41 TORRE, Juan Carlos, El gigante invertebrado. Los sindicatos en el gobierno, Argentina 19731976, Siglo XXI, Buenos Aires, 2004, p. 92.

42 Imponía penas de prisión "a los que luego de declarado ilegal un conflicto laboral, por la autoridad competente, instiguen a incumplir las obligaciones impuestas por dicha decisión..."

43 Otorgaban a las Fuerzas Armadas, primero sobre Tucumán, y luego sobre todo el territorio del país la facultad para “...ejecutar las operaciones militares y de seguridad que sean necesarias a efectos de aniquilar el accionar de los elementos subversivos...”. 
mismo año, y que tuvo una importante repercusión en la zona que estudiamos. Finalmente tomaremos el año '78 completo, donde la conflictividad vuelve a asumir características menos frontales y abiertas, aunque con un desarrollo diferente.

\subsection{De marzo del '76 a junio del '77. La resistencia molecular}

Durante los 15 meses que transcurren entre marzo de 1976 y junio de 1977, primer sub período que hemos demarcado a fin de periodizar y caracterizar la conflictividad en Rosario y sus alrededores, hemos establecido la existencia de distintas confrontaciones al menos en 25 fábricas y sectores de trabajo.

En estos primeros meses se observa una preeminencia de la protesta silenciosa y aislada. Fueron frecuentes las "huelgas de brazos caídos" y trabajo "a desgano" o "a tristeza". Este tipo de medidas hallamos en John Deere, Massey \& Ferguson, Celulosa Argentina, Cindelmet, Sulfacid, Electroclor, PASA, YPF de San Lorenzo, Cerámica Río Paraná, Luz y Fuerza, Diario La Capital, Ferroviarios, Telefónicos y pequeñas y medianas metalúrgicas como CURA, Colby, Fader, Navarro, Helvética y Daneri.

Una práctica que se advierte en numerosas ocasiones, es la de circulación de petitorios firmados por la totalidad de los trabajadores para exigir aumentos salariales o solicitar a los directivos cuestiones atinentes a las condiciones de trabajo. Otras veces, el descontento contenido se expresaba en el campo de lo "simbólico". Por ejemplo, el caso de Cerámica San Lorenzo: la dirección de la empresa había organizado un "banquete" de fin de año destinado a los obreros allí empleados. Cuatrocientos trabajadores se habían anotado para concurrir, pero "sólo fueron unos 150 que esperaron a que sirvieran, luego tiraron las bandejas con la comida y se retiraran silbando y gritando" ${ }^{44} \mathrm{O}$ en Sulfacid, donde se hicieron pintadas sobre un automóvil del Ejército con la consigna: "Fuera milicos asesinos", mientras los agentes castrenses vigilaban el orden en la producción. ${ }^{45}$

Otro modo de protesta utilizado durante el período fue el sabotaje a la producción, infraestructura o instalaciones. Hubo un sabotaje al grupo electrógeno de la planta John Deere en el momento en que entraba "un escuadrón militar para sofocar una huelga que llevaba 48 horas"; 46 en el frigorífico Swift "toneladas de las mejores carnes argentinas destinadas a ser embarcadas para la exportación, quedaron inutilizadas al ser pinchadas las cámaras frigoríficas que las conservaban", ${ }^{47}$ mientras que en el Puerto de Rosario -donde se habían producido serios conflictos durante el mes de enero del ' 77 - el 9 de febrero se produjo

44 Evita Montonera, Año 3 N 19. sept/oct.1977.

45 BASCHETI, Roberto, Documentos 1976-1977. Golpe Militar y resistencia popular. V. I, De la Campana, Buenos Aires, 2001, p. 306.

46 Ídem, p. 307.

47 El Combatiente, Año IX, № 233. 15/9/1976. 
"un caso insólito y que nunca se habría registrado en nuestra ciudad... se "rajó" un silo comenzando a perder trigo que se encontraba allí almacenado". 48

Estas formas que adquiere la confrontación están sin dudas ligadas a las durísimas condiciones que la dictadura impuso a los trabajadores a través de las distintas medidas que hemos descripto previamente.

Como señalábamos, la mayor parte de los conflictos respondieron a la lógica que hemos denominado resistencia molecular. No obstante hubo dos casos que rompen con este esquema. Son los conflictos en Luz y Fuerza (octubre 1976-marzo 1977 y noviembre de 1977) y el de los Portuarios (enero 1977). Ambos, por otra parte, tienen la particularidad de que se suceden en simultáneo con luchas del mismo gremio en Buenos Aires.

El caso de Luz y Fuerza fue una de las experiencias más radicales de conflictividad durante los primeros años de la dictadura. Entre octubre de 1976 y marzo de 1977, y en noviembre de este último año, se produjeron gran cantidad de conflictos con epicentro en SEGBA: ${ }^{49}$ hubo apagones sorpresivos y sabotajes, "trabajo a tristeza", e incluso distintas manifestaciones públicas. ${ }^{50}$

En Rosario el derrotero y las modalidades de la conflictividad fueron similares. En octubre del ' 76 el diario La Capital informaba:

...los trabajadores nucleados en el Sindicato de Luz y Fuerza, exteriorizaron su oposición a la implantación del Código Laboral que anula cláusulas de su convenio de trabajo; en demanda de reivindicaciones salariales y en señal de protesta por la detención y despido de dirigentes y empleados.

Según el matutino:

en los respectivos sitios de tareas, se aplicó el trabajo a reglamento -algunos lo denominaron "a desgano"- culminando la jornada con una marcha...

También entre el 4 y el 20 de febrero se produjeron numerosos conflictos paralelamente con los que acaecían en Buenos Aires. En ese transcurso -el 10 de febrero-y en el marco de las negociaciones, se produciría la desaparición del máximo referente del sindicato a nivel nacional, Oscar Smith.

El conflicto del puerto tuvo lugar entre el 20 y el 25 de enero de 1977, coincidiendo también con medidas nacionales. Apenas iniciado la prensa local informaba que se les aplicaría a los huelguistas "la ley de seguridad", en tanto que el prefecto principal de la zona Rosario

48 La Tribuna, Rosario, 9/02/ 1977.

49 Servicios Eléctricos del Gran Buenos Aires.

50 Ver: POZZI, Pablo, Oposición..., Op. Cit.; GHIGLIANI, Pablo, "El conflicto de Luz y Fuerza....", Op. Cit.

51 La Capital, Rosario, 28/10/1976. 
anunciaba que se garantizaría "la libertad de trabajo" y destacaba que habilitarían "nuevas tarjetas de estibadores, contándose con 400 personas que se ofrecieron a trabajar". ${ }^{52}$ El 25 se anunciaba, por el mismo medio, que el conflicto había sido solucionado. No obstante, pocos días después se producía el "insólito suceso" (sabotaje) que apuntábamos antes.

Sobre estos conflictos y sus particularidades nos parecen muy pertinentes las observaciones que en su momento hizo Rodolfo Walsh:

...solamente sectores del peronismo sindical -Luz y Fuerza y portuarios- han conseguido frenar el avance enemigo librando conflictos que terminaron en empate. La posibilidad de tal resultado está dada en ambos casos por la naturaleza crítica de la producción, que es permanente en el caso de los servicios eléctricos, y estacional en el servicio portuario (próxima exportación de cosechas). En el caso de Luz y Fuerza debe computarse además la permanencia de una organización reivindicativa de calidad superior.... ${ }^{53}$

Las particularidades que le permitieron a ciertos colectivos de trabajadores protagonizar conflictos que pudiesen superar los límites del aislamiento, dispersión y silencio mediático, será un tema que abordaremos y problematizaremos en el tratamiento de los puntos que siguen.

\subsection{Las "olas" de conflictos de 1977}

Durante la segunda mitad del año ' 77 , se produjeron dos grandes oleadas de conflictos: una con epicentro en Rosario y otra de alcance nacional, pero que repercutió también en nuestra zona de estudios. A continuación analizaremos cada una por separado.

\section{2a. El otoño caliente de junio de 1977}

En el mes de junio de 1977 se produce una ruptura en la tendencia que expresaba la conflictividad hasta ese momento. Entre el 8 y el 21 de ese mes hubo 15 días de conflictos ininterrumpidos. En ese transcurso se produjeron una serie de medidas gremiales simultáneas: dos grandes huelgas en las fábricas de tractores -que persistieron durante toda la quincena-, y una serie de reyertas de diverso tenor en distintas plantas industriales y lugares de trabajo de la zona. ${ }^{54}$

El lunes 13 junio, comenzaba la "ola" cuando se declaraban en huelga los trabajadores de las dos plantas de tractores de la zona: John Deere y Massey \& Ferguson. Desde el 8 del mismo mes se venían produciendo confrontaciones entre patronales y obreros a raíz de

52 La Tribuna, Rosario, 21/1/1977.

53 WALSH, Rodolfo, Los papeles de Walsh, Cuadernos del Peronismo Montonero Auténtico, 1979, p.11.

54 Estudiamos con más detalle estos conflictos en: CARMINATI, Andrés, "Conflictividad obrera...", Op. Cit. 
un pedido de aumento cercano al 40\%; que fuera rechazado a ambos casos. Entre tanto, el mismo 13, se produjeron dos huelgas en las empresas Fate y Sulfacid, también por motivos salariales. Durante el transcurso de esa semana, la conflictividad se fue extendiendo a otras fábricas de la región: PASA, Duperial, Celulosa, Electroclor, Argental, y "otras plantas menores elaboradoras de maquinaria para el agro". 55

El viernes 17, los trabajadores rurales y estibadores de Santa Fe iniciaban un paro por 24 horas, a la par que entraban en huelga los/as trabajadores/as de la textil Estexa y de Grandes Cristalerías de Cuyo. En estas últimas el reclamo también era de tipo salarial, pero se dio la particularidad que también expresaron su solidaridad y "adhesión al personal de John Deere y Massey Ferguson". ${ }^{56}$

Las huelgas en las fábricas de tractores se sostuvieron por 9 días. Sin lugar a dudas los dos conflictos de carácter abierto más extensos de la región en 15 meses de dictadura. A poco de comenzadas fueron ilegalizadas en función de la vigencia de la ley $21400 .{ }^{57}$ Frente a esto, los trabajadores "transformaron el paro en "huelga de brazos caídos en los lugares de trabajo", 58 por lo que ambas empresas solicitaron intervención de la policía, que procedió a desalojar violentamente las dos plantas.

Por su parte, los huelguistas de Estexa y Grandes Cristalerías de Cuyo sufrieron la misma suerte: ilegalización de los conflictos e intervención policial. En las Cristalerías, el conflicto se "solucionó" luego de que la policía detuvo a "180 operarios, los que fueron conducidos a la alcaidía de la jefatura y a la comisaría décima". 59

En el resto de los establecimientos que mencionábamos al iniciar este apartado se produjeron pequeños conflictos más propios de la denominada resistencia molecular (trabajo a desgano, paros parciales, petitorios). Con la salvedad de que en este caso se dieron de manera simultánea a otros conflictos de la región.

Con esta serie de conflictos queda planteado nuevamente el problema de comprender cuáles eran las condiciones necesarias para producir huelgas de carácter abierto (como había sucedido en Luz y Fuerza y portuarios) y de manera simultánea.

Como la dictadura había suspendido las paritarias y los aumentos de salario se producían vía decreto, Ricardo Falcón ha sostenido que "los picos de generalización de luchas por demandas salariales, coincidieron en muchas ocasiones, con el momento de otorgamiento de

55 Clarín, Buenos Aires, 22/6/1977.

56 Partes Policiales (PP). No 142, 17/06/1977, caja 55, Archivo de la Memoria Provincia de Santa $\mathrm{Fe}$ (AMPSF).

57 Que prohibía “toda medida concertada de acción directa, paro, interrupción o disminución del ritmo de trabajo", bajo amenaza de penas de "prisión de uno a seis años", constituyéndose además en "causal de despido justificado. Ley 21400, Boletín Oficial, 8/9/1976.

58 Clarín, Buenos Aires, 18/06/1977.

59 El País desde Rosario, Rosario, 22/06/1977. 
reajustes por decreto". ${ }^{60}$ En marzo de 1977 el ministro de economía Martínez de Hoz había impuesto una "tregua" de 120 días para precios y salarios. Esta medida había producido un deterioro mayor del poder adquisitivo de los trabajadores, que ya venía disminuyendo progresivamente. Para el mes de junio se avizoraba el fin de la "tregua", lo que pudo ser una causa que empujara a distintos sectores de trabajadores a reclamar por un reajuste salarial de manera simultánea.

Ahora bien, la industria del tractor, cuyos obreros cumplieron sin dudas un rol protagónico en estas jornadas, no representa un "sector crítico", ni sus trabajadores poseen una "posición estratégica", como denomina John Womack Jr., a la capacidad de "algunos obreros detener la producción de muchos otros", ${ }^{11}$ por el lugar que ocupan en la producción. No obstante, y a manera de hipótesis, nos parece que -sumado al malestar, que era generalizado- la aparición de dos grandes conflictos que por su dimensión pudieron saltar el cerco del silencio y la censura, alentó a otros trabajadores a reproducir las medidas en otras fábricas y lugares de trabajo. ${ }^{62}$ Por otra parte, si bien ya venían sufriendo severas reducciones en su personal de planta, se trataba de dos fábricas de grandes dimensiones: en junio de 1977 John Deere contaba con 1200 trabajadores y Massey con 800 .

\section{2b. La ola de huelgas de octubre/noviembre de 1977. La conflictividad sobre rieles}

Apenas cuatro meses más tarde una ola de huelgas que adquirió dimensiones nacionales y que movilizó cerca del millón de trabajadores, tuvo enorme repercusión en la región de Rosario y sus alrededores.

Este movimiento huelguístico fue caracterizado por la mayoría de los observadores como el momento más complicado por el que atravesaba el régimen desde su instauración. Un editorial del diario La Nación señalaba que era "la primera vez, en más de diecinueve meses, que el Gobierno debió enfrentar un conflicto gremial cuyas consecuencias perturbaron seriamente el interés público", ${ }^{63}$ en tanto que en algunas columnas periodísticas se debatía si los hechos eran o no comparables al Cordobazo. ${ }^{64}$

60 FALCÓN, Ricardo, "La resistencia...", Op. Cit., p. 127.

61 WOMACK Jr., John, Posición Estratégica y Fuerza obrera. Hacia una nueva historia de los movimientos obreros, Fondo de Cultura Económica, México, 2007, p. 50.

62 Si bien las noticias son breves, se informa sobre los conflictos tanto en la prensa local como de Buenos Aires: La Capital (15, 16 y 18/06/1977); El país desde Rosario (15, 16, 17, 18, 21, 22 y 23/06/77) La Tribuna (17, 18, 22 y 23/06/1977) de la ciudad de Rosario; Clarín (17, 18, 22, 23 y 24/06/77), La Nación (16,17, 18 y 19/06/1977), La Prensa (16, 18 y 19/06/1977) y La Razón (17/06/1977) de la ciudad de Buenos Aires.

63 La Nación, Buenos Aires, 31/10/1977.

64 La Razón, Buenos Aires, 5/11/1977; La Nación, Buenos Aires, 6/11/1977. 
Con sus alzas y bajas, la conflictividad se extendió durante 40 días y afectó a los principales centros urbanos del país, con epicentro en Buenos Aires.

El primer conflicto importante, y que abre la ola de conflictividad, se dio de manera aislada en la planta de IKA Renault en Córdoba, el 11 de octubre. Fueron siete días de huelga, con una gran repercusión mediática.

Nueve días después, estalló una huelga en el ferrocarril que, de un simple paro de "señaleros" de la línea Roca, se transformó en una huelga en todos los ramales y al menos en 6 provincias (Buenos Aires, Córdoba, Mendoza, Santa Fe, Entre Ríos, Tucumán). Casi paralelamente se desataron conflictos entre pilotos y personal aeronáutico, en el transporte de corta, media y larga distancia, en todas las líneas de subterráneos, entre personal de Luz y Fuerza en Buenos Aires y Rosario y en los puertos rosarino y porteño.

En Rosario y su zona se produjeron conflictos en las líneas Mitre, Belgrano y los talleres de Pérez y Villa Diego del Ferrocarril Mitre, en Agua y Energía (Rosario, Villa Constitución y San Lorenzo), en el Puerto, Empleados de Comercio, Recolectores, Ministerio de Obras públicas, Junta Nacional de Granos, Correos y Telecomunicaciones, Obras Sanitarias, Banco Nación, YPF San Lorenzo, PASA, Acindar, Editorial Caille y Vola y CAP (Corporación Argentina de Productores de Carne). En tanto que los partes de la policía informaban que se habrían "detectado reuniones de dirigentes medios" de la UOM que estarían proyectando "una movilización de sus afiliados en demanda de mejoras laborales". ${ }^{65}$

A lo largo de los 40 días que se mantuvo la conflictividad en los principales centros urbanos del país, se pudo observar de qué manera se condensaron y combinaron las distintas experiencias de lucha y resistencia, luego de diecinueve meses de dictadura. Por un lado, concertadamente con la lucha abierta se produjeron diferentes formas de enfrentamiento características de la denominada resistencia molecular: sabotajes, "trabajo a desgano", y sobre todo se advierte claramente que las medidas y formas de lucha apuntaban a "no brindar blancos visibles a la represión". Relacionado con esto último, comienza a manifestarse, tanto por boca de funcionarios como de analistas políticos y periodistas, la cuestión de la "falta de interlocutores válidos" para negociar la finalización de las huelgas, ${ }^{66} \mathrm{y}$ en consecuencia la necesidad de implementar una nueva Ley de Asociaciones Profesionales que regule la actividad sindical.

La paralización del ferrocarril en el Gran Buenos Aires y parte del país, sumado a la interrupción de otros servicios públicos, como la energía, aviones, subterráneos y el transporte de pasajeros era imposible de invisibilizar y poseía per se una capacidad disruptiva

\section{PP. N²49 - Caja 55- 2 /11/1977, PP. N²50 - Caja 55- 3/11/1977 en AMPSF.}

66 Por ejemplo, Clarín subrayaba que durante los conflictos se evidenció la "ausencia de un interlocutor válido que permitiera encauzar las conversaciones entre las autoridades y los trabajadores", 3/11/1977; mientras que La Nación sostenía que las huelgas se habían extendido a causa de "la ausencia de representantes válidos de los obreros, de dirigentes capaces de expresar las verdaderas aspiraciones de éstos" 7/11/1977. 
del orden. Nuevamente aparece aquí la cuestión de la posibilidad que tienen algunos trabajadores trascender al espacio público con sus reclamos y de convertirse incluso en motores de otros conflictos. En el caso de los obreros del riel, además, ostentan la particularidad de estar comunicados y extendidos a través de la vía férrea, lo que les permite, casi de manera natural, propagar el conflicto sobre el espacio nacional.

\subsection{8: Crisis, resistencia molecular y sabotajes}

Luego de las grandes convulsiones del año '77, durante 1978 la conflictividad tendió a recluirse nuevamente en la resistencia molecular.

No obstante nuestros registros contabilizan alrededor de 34 conflictos, de diversa intensidad y duración, en 24 plantas o lugares de trabajo distintos. En algunos de estos lugares se evidencia una persistencia de la conflictividad registrada durante momentos previos, como por ejemplo ferroviarios, luz y fuerza, portuarios, John Deere, Celulosa y Sulfacid.

En el transcurso del año no se produjo ningún estallido u ola de conflictos, y por lo general se acentuó la invisibilidad de los conflictos en la prensa. Solamente trascendieron a los periódicos, la huelga del personal de conducción de media y larga distancia, que se produjo en enero -prácticamente el último coletazo de la ola de huelgas de octubre-noviembre-dos huelgas en los ferroviarios y una gran huelga en el frigorífico Swift, que duró casi una semana. Es probable que, entre otros factores, la celebración del Mundial de Fútbol Argentina ' 78 se haya convertido en un potente silenciador del conflicto social.

Por otro lado, a partir de este año, comienzan a hacerse palpables los efectos de la segunda etapa de la política económica de Martínez de Hoz sobre la industria (profundización de la apertura comercial y reforma financiera). Por ello muchos conflictos tuvieron origen en el malestar creado por procesos de despido y racionalización, aunque el principal detonante siguió siendo el reclamo salarial.

Una de las particularidades que detectamos durante 1978 fue la gran cantidad de hechos de sabotaje que se produjeron: 7. Además de 3 atentados con "artefactos explosivos". Estos últimos se contabilizan aparte pues carecemos de información precisa, y debido a que podrían haber sido cometidos sin participación directa de los trabajadores. Aunque sí estuvieron relacionados a la conflictividad: dos se produjeron contra transformadores de luz eléctrica y uno en la puerta de Fate.

Nos detendremos brevemente en algunos de estos hechos, porque sin lugar a dudas dicen mucho sobre las confrontaciones del período.

Una de las fábricas donde se produjeron diversos actos de sabotaje fue Celulosa Argentina. En el mes de abril se sabotearon las "máquinas fabricadoras de papel, hecho que fue

perpetrado arrojando en el interior de las mismas bulones que produjeron la inutilización de las mismas". ${ }^{67}$ 
Según la información que recogían los partes policiales:

...los obreros de Celulosa Argentina estaban en conocimiento de futuros despidos masivos de personal, los que serían reemplazados con jubilados de este gremio, contratados, al efecto. ${ }^{68}$

Al mes siguiente se produjo un incendio en la "Sección Maderas, Rechazo de Papel y Depósito de Papel", ${ }^{69}$ mientras que el 27 de octubre se saboteó la máquina " $\mathrm{N}^{\circ} 2$ de "papel" a la que se le arrojó un trozo de "asfalto". ${ }^{70}$

Otro caso similar se dio en Cerámica Alberdi, donde se produjeron varios hechos de sabotaje consecutivos. Los mismos iban atados a una serie de conflictos entre patronal y obreros que giraban alrededor de varias cuestiones: despidos, la representación gremial de los trabajadores y la urgencia de aumentos salariales.

Los sabotajes buscaban, en este caso, afectar la producción retrasándola. Por ejemplo:

... el día 20-02-78, a las 5,00 horas, denuncia el capataz de Cerámica Alberdi, que al poner en funcionamiento la máquina $\mathrm{N}^{\circ} 2$ de elaboración de materia prima, no funcionaba. La desarmó para hallar la avería y encontró un hierro de 12 centímetros de longitud por 6 centímetros de ancho... Dicha máquina estuvo sin producir desde las 1 hasta las 11,000 horas, de ese día... ${ }^{71}$

A través de "panfletos" de la Agrupación de Trabajadores Ceramistas, que la policía halló en las inmediaciones, podemos saber que las demandas eran:

... que se nombre asamblea para nombrar un comisión que exija al directorio de Empresa aumento inmediato de sueldo... no al despido masivo, no a las mangos por acuerdo de renuncias... Reingreso a cualquier lugar de la fábrica de los dirigentes ${ }^{72}$

Los dos casos exponen, a nuestro entender, las formas que asume la conflictividad ante un escenario que presenta escasas posibilidades de negociación y donde el panorama para los trabajadores era siempre de "derrota". La experiencia parecía indicar que si lograban organizarse, a pesar de los peligros, la huelga era ilegalizada, si mutaban las formas de acción hacia modalidades tales como las huelgas de "brazos caídos", la policía o el ejército intervenían en las plantas y detenían, despedían o amenazaban trabajadores, etc. A ello se sumaba el contexto recesivo de la industria que planteaba un horizonte de cierres y racio-

68 Ibídem.

69 PP, D.2, No 300800May78, Caja 56, 30/05/1978 en AMPSF.

70 PP, D.2 270800Oct78, Caja 56, 27/10/1978 en AMPSF.

71 PP, D.I.N 33 , caja 55-B, 22/02/78 en AMPSF.

72 Ibídem. 
nalización. Frente a estas circunstancias pareciese que la única forma de presionar o de "igualar" fuerzas en la confrontación era el sabotaje.

\section{Consideraciones Finales}

En el presente trabajo hemos procurado presentar las diversas modalidades que asumió la conflictividad obrera en Rosario y las zonas aledañas durante los primeros años de la última dictadura militar.

Una primera conclusión que se desprende del trabajo indica que, aunque muchas veces aislada y con escasa repercusión, la conflictividad se manifestó durante todo el período escogido. El estudio año por año nos permitió trazar periodizaciones en función de las particularidades que fueron asumiendo los conflictos.

Se puede inferir que la preeminencia de la denominada resistencia molecular está asociada a las duras condiciones que la dictadura había impuesto a los trabajadores: una fuerte política represiva (legal y extra legal), una decidida intervención en los conflictos a favor de las patronales mediante el uso de las fuerzas policiales y/o militares, la prohibición y neutralización de todas las formas organizativas de los trabajadores (sindicatos, comisiones internas, coordinadoras de base, delegados, etc.). Esta serie de condicionamientos tendió a recluir los conflictos en las fábricas y lugares de trabajo, aislándolos muchas veces de otros sectores. Esto produjo también algunas mutaciones en el accionar de los trabajadores. Los hechos de sabotaje, en particular los del año '78, donde se ve claramente la relación entre los reclamos irresueltos y los atentados contra las instalaciones fabriles, son una clara muestra de la transformación de los modos de protesta condicionados por la coyuntura.

Por otra parte, a lo largo del escrito hemos procurado reflexionar acerca de las particularidades de ciertos sectores de trabajo, y las posibilidades que su ubicación en el proceso productivo les daba para provocar hechos relevantes, o incluso convertirse en catalizadores de otros conflictos.

Abordamos el caso de los trabajadores de Luz y Fuerza, cuya ubicación estratégica les permitió confrontar abiertamente al régimen, aún en los momentos más duros. Sin embargo el gremio fue muy golpeado por la represión: sufrió la desaparición de al menos una treintena de trabajadores incluyendo al Secretario General del sindicato; al margen de otro tipo de represalias. Dado el carácter "crítico" del sector, los "lucifuercistas" pudieron resistir seriamente la política del gobierno de facto, que buscaba producir una racionalización, privatización y ajuste del sector. No obstante sus luchas padecieron las mismas limitaciones que otras ramas y sectores: no lograron exceder los marcos del gremio.

Durante 1977 analizamos dos procesos de huelga que trascendieron los marcos fabriles y aún sectoriales. En el primero observamos la influencia que tuvieron las huelgas prolongadas de dos grandes fábricas de la región del Gran Rosario. La posibilidad de que estos conflictos atravesaran el silencio mediático, sumado al malestar generalizado y a la 
posibilidad cierta de reajustes salariales, operaron como motor de un estallido simultaneo de huelgas a nivel regional.

En una segunda instancia estudiamos la importancia del gremio ferroviario, que al igual que los casos de Luz y Fuerza y Portuarios, consigue producir conflictos que no pueden ser invisibilizados. Estos trabajadores, por su ubicación estructural, pudieron operar como impulsores de otros conflictos. La propia paralización del ferrocarril, sobre todo en el conurbano bonaerense, se convertía en un obstáculo para el normal funcionamiento de otras industrias. Por otra parte, el contexto de demandas candentes en todos los sectores de trabajo, hizo que una huelga de un pequeño gremio del ferrocarril -los señaleros-accionara como una chispa en el pajonal seco.

En general, como hemos señalado, la conflictividad del período padeció el aislamiento producido por la práctica anulación de cualquier órgano de coordinación. Aparentemente, a causa de esta ausencia de un espacio de articulación oficial, los estallidos de conflictividad necesitaron de algún sector o gremio que por sus capacidades estructurales, por su tradición histórica o por el peso numérico de los trabajadores de la fábrica o sector pudiese encabezar el reclamo.

En un aspecto más general, coincidimos con la apreciación de Ricardo Falcón cuando señala que "las luchas sindicales durante el "Proceso" lograron poner límites precisos a la política gubernamental y a las iniciativas de las empresas, pero no pudieron impedir retrocesos en el orden global". ${ }^{73}$ Por otra parte, durante el período escogido en nuestro estudio, ningún otro sector social o político -salvo las solitarias rondas de las "Madres"- había enfrentado de ninguna manera a la dictadura.

Recibido: $14 / 04 / 2012$

Aceptado: 15/07/2012

73 FALCÓN, Ricardo "La resistencia...", Op. Cit., p.136. 